International Journal on Applied Bioengineering, Vol. 6 No. 2 July 2012

\title{
STRUCTURAL CHANGE AND STABILITY OF SOLUBILIZED BACTERIORHODOPSIN
}

\author{
Yuri Mukai ${ }^{1}$, Takanori Sasaki ${ }^{2}$ \\ 1,2Department of Electronics and Bioinformatics, School of Science and Technology, \\ Meiji University, Kawasaki, Japan \\ Email: ${ }^{1}$ yuri@isc.meiji.ac.jp
}

Abstract

The structural stability of bacteriorhodopsin (bR) solubilized with $n$-octyl- $\beta$-glucoside $(\mathrm{OG})$ at various concentrations were evaluated and the effects on inter/intra molecular interaction were examined by comparison with the case of solubilization with Triton X-100 (TX). Solubilized bR with OG had the conditions occurred only thermal bleaching without photobleaching, whereas TX solubilized bR not occurred thermal bleaching but photobleaching. Under these conditions, OG solubilized $\mathrm{bR}$ showed symmetrical bilobed exciton band that indicate remain of protein-protein interaction in the visible region by circular dichroism (CD) measurements. On the other hands, that of bR solubilized with TX were broad positive bands that indicate the retention of intra-molecular local conformation. Thus the effect on inter/intra molecular interaction and tertiary structural stability of $b R$ was remarkably different though both $O G$ and $T X$ are non-ionic detergents. It was also suggested that the stability of $\mathrm{bR}$ in the ground state required the retention of intra molecular interaction, and intermolecular interaction was necessary to keep $\mathrm{bR}$ in function stable, based on correlation between the kinetics of thermal/photo bleaching and visible $C D$. The $C D$ spectra in visible region could be non-destructive indicator of structural stability of $b R$.

Key words: bacteriorodopsin, circular dichroism, detergent, photobleaching, structural stability

\section{INTRODUCTION}

Bacteriorhodopsin (bR), a light-driven proton pump found in Halobacterium salinarum (1), has seven transmembrane helices and forms 2D crystalline structure with hexagonal symmetry of trimer as a unit $(2,3)$. On photo-excitation, bR shows a cyclic photochemical reaction, the so-called photocycle, involving various photointermediates $(K, L, M, N$, and $O)$, each of which has a different absorption maximum $\left(\lambda_{\max }\right)$ due to conformational changes during the photocycle $(4,5)$. By the progress in structural biology recently, the molecular structures in the photointermediate states of $b R(6-8)$ have determined as well as the ground states (9-11). Even though visible-light is the trigger of $b R$ function, it is known the dysfunctional phenomenon of $\mathrm{bR}$ caused by visible-light, called photobleaching. In native purple membrane (PM), intermolecular interaction in the 2D crystalline structures and intra-molecular interaction in the bR molecule are well balanced, and not only ground state of bR but the photocycle is maintained without thermal bleaching or photobleaching. However, under the condition occurred thermal bleaching or photobleaching, bR hydrolyzed at Lys216 Schiff-base and denature into bacterioopsin $(\mathrm{bO})$ and free retinal. Thermal bleaching and photobleaching are the important phenomenon which indicated the stability of the $\mathrm{bR}$ in ground state and photocycle, respectively.
Photobleaching of $\mathrm{bR}$ was addressed in previous studies (12-20). These indicated that $b R$ undergoes photobleaching when illuminated at high temperatures (12-15), at alkaline $\mathrm{pH}(16,17)$ and is solubilized (18-20), suggesting that some photointermediates are less stable than the ground state of $b R$, or another branch that leads to photobleaching is produced. These also imply that protein-protein interaction in the 2D crystalline structure is responsible for photobleaching of $\mathrm{bR}$.

We have studied the stability of solubilized $b R$ with non-ionic detergent as $n$-octyl- $\beta$-glucoside (OG) and Triton X-100 (TX) in the dark and under illumination. When 2D crystalline structure of $b R$ was destroyed by solubilization with $50 \mathrm{mM}$ of $\mathrm{OG}$ concentration, photobleaching were observed even at room temperature (18). It was indicated that solubilization is an effective method to study of the influence of 2D crystalline structure for structural stability of bR. However, it was difficult to separately examine thermal bleaching and photobleaching at that condition because solubilized $b R$ was unstable not only under illumination but in the dark. On the other hand, when the stability of solubilized bR with TX was evaluated and the oligomerization state of protomers was observed, not thermal bleaching but photobleaching occurred when the protein-protein 
interaction was disappeared (19). It strongly supported that the protein-protein interaction was main origin of stabilization of $b R$ in function. Though $O G$ and $T X$ are well-known mild non-ionic detergents and they are often used for the solubilization of membrane proteins for 3D structural analysis, those both may have quite different effect for destabilization on bR. The systematical evaluation is necessary to elucidate the difference of effect on structural stability of $b R$.

In the present study, we compared the properties for structural stabilization of $b R$ solubilized with various concentrations of $O G$ with native and TX-solubilized $b R$. The structural stability of $b R$ solubilized with $O G$ was evaluated in the dark and under illumination using absorption spectral measurement. In addition, inter/intra molecular interactions of solubilized bR were monitored using visible circular dichroism (CD) spectral measurement. Interestingly, thermal bleaching and photobleaching kinetics and $C D$ spectra in visible region of solubilized $b R$ with $O G$ were quite different from TX-solubilized $b R$. The rate constant of thermal bleaching was enhanced significantly in OG-solubilized $\mathrm{bR}$ accompanied with increase of detergent concentration up to $40 \mathrm{mM}$, while there were conditions only photobleaching was occurred in TX-solubulized $b R$ (19). About 40 to $50 \mathrm{mM}$, the rate constant of photobleaching was enhanced depending on $O G$ concentration. Visible $C D$ spectrum of PM is highly sensitive to the oligomerization state of protomers and shows exciton coupling between neighboring protomers (21-23). When bR solubilized from PM with TX, the CD band with a bilobe profile is replaced with a broad positive band (19). In contrast, OG solubilized bR exhibits symmetrical bilobe with low concentration and flat with high concentration even though absorption at $\lambda_{\max }$ still remained. In this report including the interpretation of these unique $C D$ bands coincident with previous report (24), the properties for structural stabilization of bR was discussed correlation between visible $C D$ band with thermal and photobleaching kinetics by comparing the case of OG with TX.

\section{METHODS}

\section{A. Sample preparations}

PM from Halobacterium salinarum, strain R1M1, was prepared according to the method of Oesterhelt and Stoeckenius (25). PM was suspended in $10 \mathrm{mM}$ Tris/ $\mathrm{HCl}$ buffer (pH 7.0). n-octyl- $\beta$-glucoside (OG), which was purchased from Wako Chemical Co. (Tokyo), was added to PM suspension at final concentrations ranging from $10 \sim 100 \mathrm{mM}$. bR concentration of the mixture was approximately $10 \mu \mathrm{M}$, it was calculated from the absorption maximum at 568 $\mathrm{nm}$ using the molar extinction coefficient of 62700 $\mathrm{M}^{-1} \mathrm{~cm}^{-1}$. After incubation for 2 hours at $37^{\circ} \mathrm{C}$ in the dark, the sample was centrifuged at $105,000 \mathrm{~g}$ for 60 minutes at $4^{\circ} \mathrm{C}(\mathrm{L}-60$, Beckman Co.).

\section{B. Absorption and CD spectra measurements}

Absorption spectra were monitored with a diode-array spectrophotometer (HP8452A, Hewlett Packard Co.) equipped with a xenon lamp, as reported previously (18). Temperature of the cell holder was kept constant at $37^{\circ} \mathrm{C}$ by a micro-cooling circulator (RTE-8, Neslab Co.). Absorption spectra under visible-light illumination and in the dark were successively measured at intervals of 5 minutes for 1 hour, after the sample temperature adjustment. In the condition of under illumination, actinic constant illumination was provided through a sharp cut-off filter (>520 nm). Circular dichroism (CD) spectra were measured with CD spectrophotometers (J-820, JASCO) at $37^{\circ} \mathrm{C}$ in the dark.

\section{RESULTS}

\section{A. Solubilization of $b R$ with $O G$ at various concentrations}

Absorption spectra of bR solubilized with 25 $100 \mathrm{mM}$ of $O G$ are shown in Fig. $1 \mathrm{~A}$ with the spectrum of native PM as control. Below $25 \mathrm{mM}$ of OG have no significant absorption (data not shown) because bR was unsolubilized. Above $25 \mathrm{mM}$, the spectra have significantly peaks at $280 \mathrm{~nm}$ and about $560 \mathrm{~nm}$ $\left(\lambda_{\max }\right)$ due to absorption of tryptophan residue and retinal with apoprotein, approximately. Until $40 \mathrm{mM}$, absorption band at $\lambda_{\max }$ becomes remarkably stronger with increase of detergent concentration. Above $40 \mathrm{mM}$, on the other hand, the peak at $\lambda_{\max }$ hardly increased. Weak peak at $390 \mathrm{~nm}$ due to free retinal indicates thermal bleaching of $b R$ molecules was also appeared with increase of $O G$ concentrations.

To examine the solubilization degree of PM as a function of $O G$ concentration, relative absorbance of solubilized $\mathrm{bR}$ at $\lambda_{\max }\left(A_{\max } / A_{560}\right)$ was calculated compared to absorbance at $560 \mathrm{~nm}$ of unsolubilized 

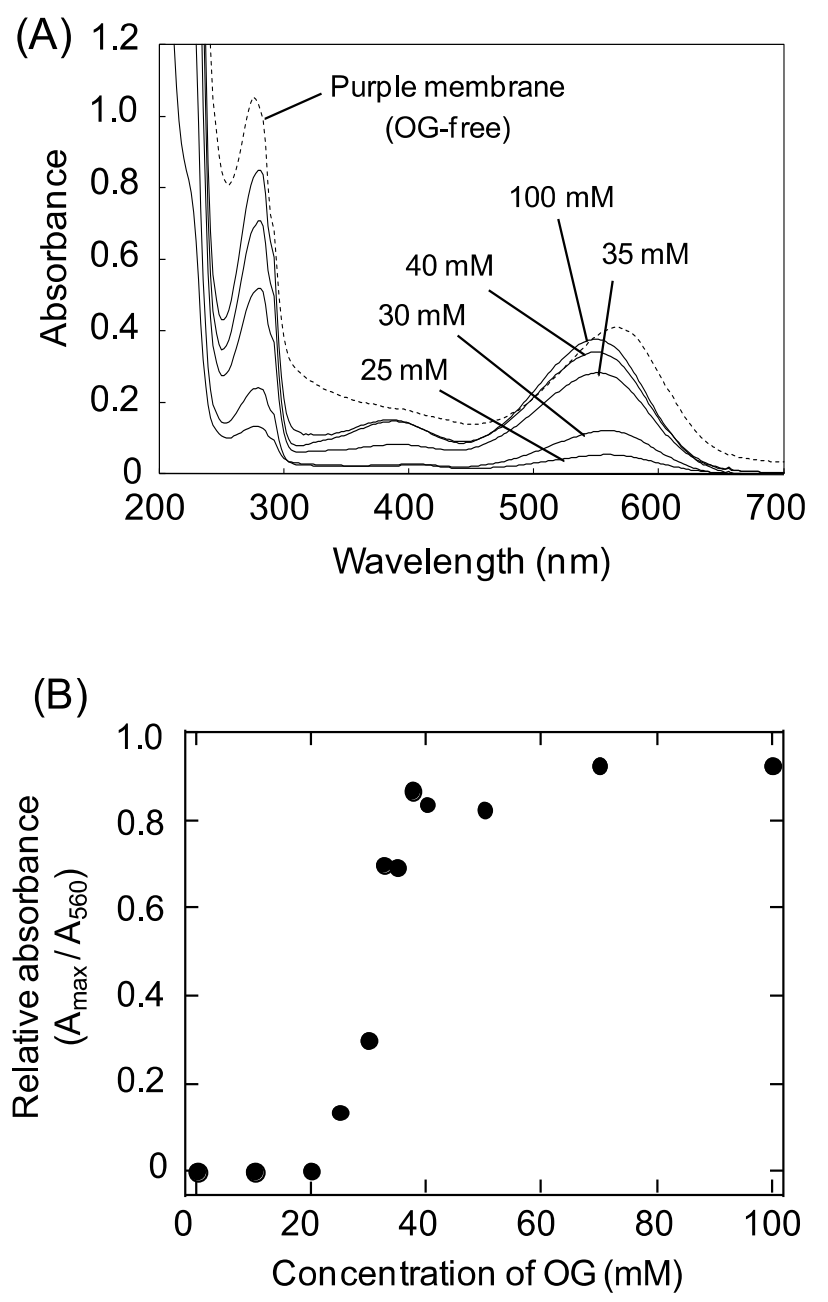

(C)

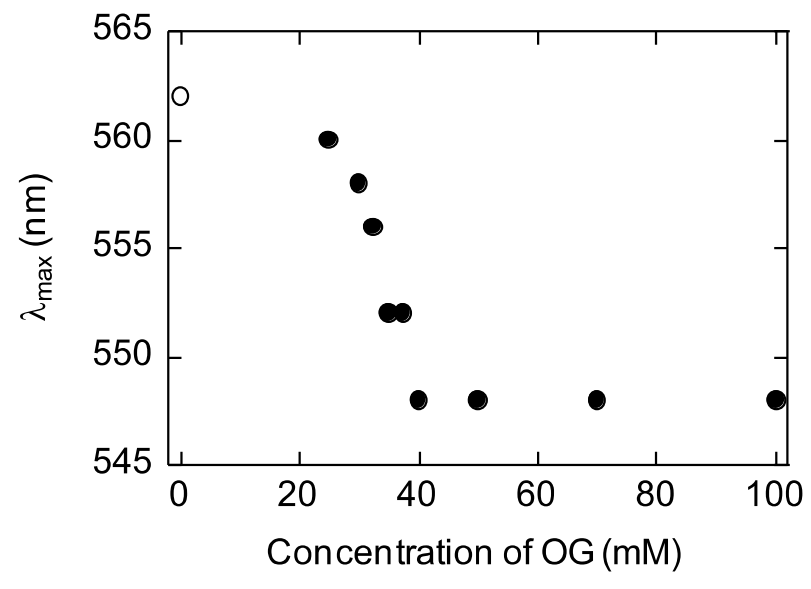

Fig. 1. (A) Absorption spectra of bR solubilized with $25 \sim 100 \mathrm{mM}$ OG. (B) Relative absorbance of bR solubilized with $25 \sim 100 \mathrm{mM} \mathrm{OG}$. (C) Shift of maximum absorption wavelength of dark-adapted $b R$ solubilized with $25 \sim 100 \mathrm{mM} \mathrm{OG}$. Opened circle (0) shows the maximum absorption wavelength of the native PM.
PM (Fig. 1B). Relative absorbance drastically starts to increase at $25 \mathrm{mM}$, and reaches to the plateau at 40 $\mathrm{mM}$ at the level of 0.85 . The profile of changes in the relative absorbance against detergent concentrations is similar to that for solubilization with TX (19).

Figure $1 \mathrm{C}$ shows $\lambda_{\max }$ of solubilized $\mathrm{bR}$ in the dark as a function of $O G$ concentration. When $O G$ concentration was increased to $40 \mathrm{mM}, \lambda_{\max }$ gradually blueshifts from $560 \mathrm{~nm}$ to $548 \mathrm{~nm}$. Above $40 \mathrm{mM}$, on the other hand, no further shift was observed. The position of $\lambda_{\max }$ of $b R$ solubilized with OG above 40 $\mathrm{mM}$ is in good agreement with the previously reported $\lambda_{\max }$ of the monomer of dark-adapted bR $(19,26)$.

\section{B. Structural stability of $b R$ solubilized with $O G$ at various concentrations in the dark and under illumination}

Figure $2 \mathrm{~A}$ shows the time-dependent changes of absorption spectra measured at $37^{\circ} \mathrm{C}$ in the dark (a) and under visible-light illumination (b) where $b R$ was solubilized with $100 \mathrm{mM} \mathrm{OG}$. The spectra were successively measured at 5-minute intervals. The decrease of the absorption peaks at $\lambda_{\max }$ was coupled with increase of the peaks at $390 \mathrm{~nm}$, isosbestic point nearly $430 \mathrm{~nm}$ was observed both in the dark and under visible-light illumination. These absorption spectral changes mean increase of free retinals because of the structural stability of solubilized $b R$ was lost. The decrease of $\lambda_{\max }$ absorption peak under illumination was much faster than that in the dark, this phenomenon is precisely photobleaching due to the denaturation of $b R$ induced by light illumination. The peak at $\lambda_{\max }$ did not reappear upon subsequent incubation at $4^{\circ} \mathrm{C}$ in the dark for 24 hours, nor did it reappear with the addition of retinal, suggesting that the absorption change was due to irreversible denaturation.

Figure $2 \mathrm{~B}$ shows the time course of relative absorbance at $\lambda_{\max }$ in the dark (a) and under visible-light illumination (b) where $\mathrm{bR}$ was solubilized with $0 \sim 100 \mathrm{mM} \mathrm{OG}$ at $37^{\circ} \mathrm{C}$. Because it was occurred not only thermal bleaching but photobleaching under visible-light illumination, the difference between the absorbance at $\lambda_{\max }$ in the dark and that under visible-light illumination is shown in (c) due to observation of net photobleaching. Changes of relative 
absorbance due to thermal and photobleaching were fitted with a single exponential decay equation, and decay time constants of each OG concentration were determined.

Plots of decay time constants for thermal and photobleaching against $O G$ concentration are shown in Fig. 2C. Decay time constants of thermal and photobleaching were sigmoidal increase above $25 \mathrm{mM}$ and $30 \mathrm{mM}$, and were saturated more than $40 \mathrm{mM}$ and $50 \mathrm{mM}$, approximately. Thermal and photobleaching were summarized in some $O G$ concentration area. Under $25 \mathrm{mM} \mathrm{OG}$, solubilized bR underwent both thermal and photobleaching. Up to $40 \mathrm{mM}$, thermal bleaching was dominant than photobleaching. More than $40 \mathrm{mM}$, thermal bleaching was saturated and photobleaching were much enhanced drastically until 50 $\mathrm{mM}$.

C. Intermolecular structural change of $b R$ solubilized with $O G$ at various concentrations

(A)

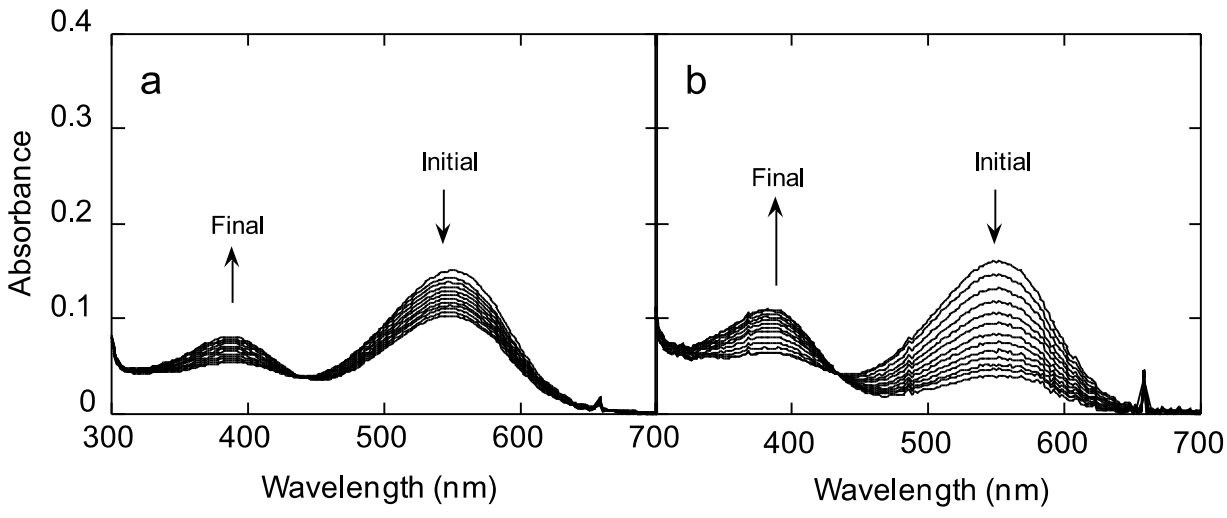

(B)

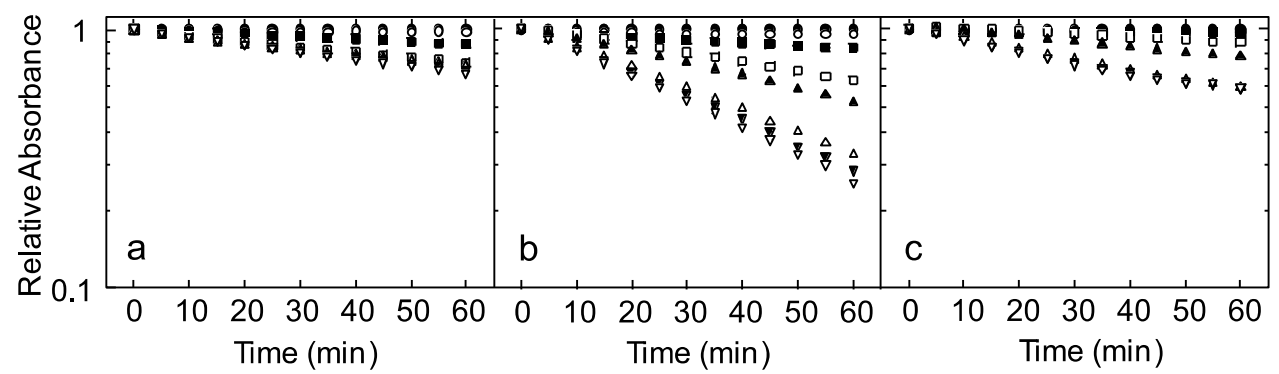

(C)

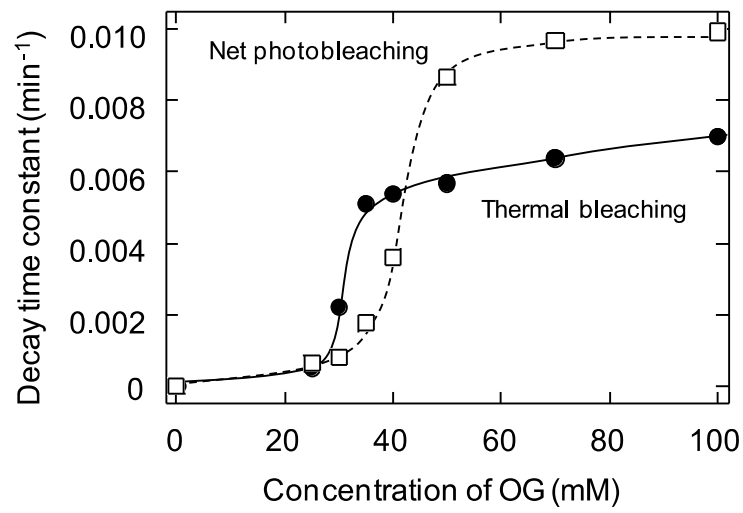

Fig. 2. (A) Absorption spectra of bR solubilized with $100 \mathrm{mM} \mathrm{OG}$ measured at 5-minute intervals. Time-dependent changes in the dark (a) and under illumination (b). (B) Bleaching kinetics of bR solubilized with $0(\mathbf{O}), 25(\bigcirc), 30$ $(\boldsymbol{\square}), 35(\square), 40(\mathbf{\Delta}), 50(\triangle), 70(\boldsymbol{\nabla})$ and $100 \mathrm{mM}(\nabla)$ OG in the dark (a) and under illumination (b). Differences between the absorbance in the dark and under illumination are plotted in graph (c). (C) Rate constants for thermal bleaching $(\mathbf{)})$ and net photobleaching $(\square)$. 
$C D$ spectra in visible regions were measured for solubilized $\mathrm{bR}$, in order to investigate changes in oligomerization states of bR (Fig. 3). Less than 32.5 $\mathrm{mM}$ of $O G$ concentration, solubilized samples were too low to obtain reliable $C D$ spectrum even with a 10 mm-long cuvette, as shown above. Visible $C D$ spectrum of $b R$ in native $P M$ shows an asymmetric band due to (i) exciton coupling between neighboring chromophores and (ii) the local chiral structure around the chromophore (21-23). Shown in Fig. 3, upon solubilization at $35 \mathrm{mM}$, visible $\mathrm{CD}$ spectra changes to almost symmetric band with the positive lobe at $\mathbf{5 3 0}$ $\mathrm{nm}$ and the negative lobe at $600 \mathrm{~nm}$ and remarkably decreases its intensity compared to native $b R$, it was very similar to the spectra indicated solubilization process in $41 \mathrm{mM} \mathrm{OG}$ reported by Dencher and Heyn (24). The symmetric weak CD band in visible region still appears at $37.5 \mathrm{mM}$, on the other hand, the visible $\mathrm{CD}$ signals diminishes almost to zero at $40 \mathrm{mM}$, although visible absorption at ?max remains strongly, as shown above. At higher detergent concentrations, solubilized samples also show flat CD signals as well as $40 \mathrm{mM}$ (data not shown). Visible $\mathrm{CD}$ band of OG-solubilized $b R$ are quite striking contrast with TX-solubilized bR which showed a single broad positive peak, irrespective of detergent concentrations (19).

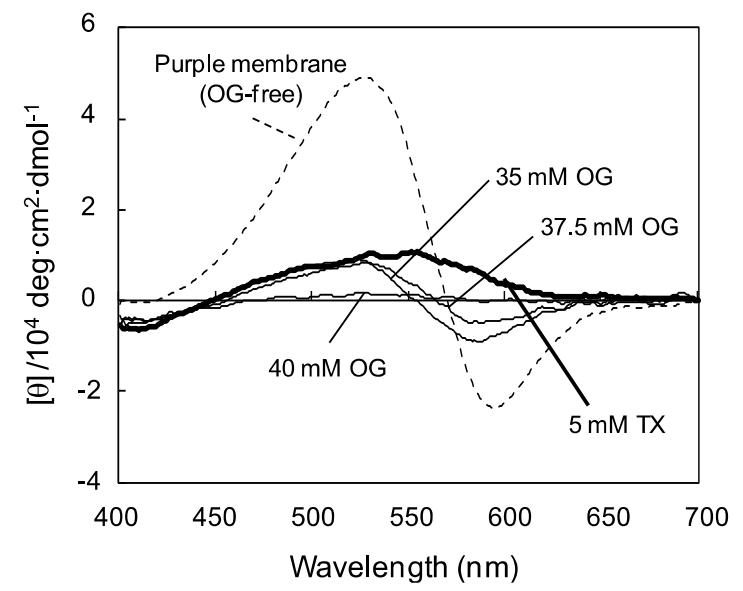

Fig. 3. $C D$ spectra in visible region of $b R$ solubilized with $35 \sim 100 \mathrm{mM} \mathrm{OG}$.

\section{DISCUSSION}

The results were summarized in Table 1 divided into two phase on the boundary of $40 \mathrm{mM} \mathrm{OG}$ concentration. (i) bR was solubilized more than $25 \mathrm{mM}$ of OG. Solubilization degrees were enhanced accompanied with increase of OG concentration up to $40 \mathrm{mM}$, and were saturated at about 0.9 above $40 \mathrm{mM}$. (ii) The $\lambda_{\max }$ of solubilized $b R$ were blueshifted from 562 to $548 \mathrm{~nm}$ accompanied with increase of $O G$ concentration up to $40 \mathrm{mM}$, and were constant at 548 $\mathrm{nm}$ above $40 \mathrm{mM}$. (iii) Structural stability of bR became lower by solubilization with $O G$ even in the dark. Below $40 \mathrm{mM}$, solubilized bR occurred only thermal bleaching almost without photobleaching. On the other hands, photobleaching was occurred dominantly above $40 \mathrm{mM}$. (iv) Visible CD spectra were uniquely changed by solubilization with $\mathrm{OG}$. Asymmetrical exciton band shown in native $b R$ changed symmetrically up to 40 $\mathrm{mM}$ of $\mathrm{OG}$, and became flat above $40 \mathrm{mM}$. These results showed that there was the turning point at 40 $\mathrm{mM}$ in structure and physical property of $\mathrm{bR}$ in the case of solubilization with OG.

Table 1. Summary of solubilization degree, $\lambda_{\max }$, visible $C D$ spectrum and structural stability on bR solubilization with $O G$

\begin{tabular}{|c|c|c|}
\hline & $\begin{array}{c}\text { Phase 1 (25 mM } \\
\leq \text { [OG] }<40 \mathrm{mM} \text { ) }\end{array}$ & $\begin{array}{c}\text { Phase 2 ([OG] } \\
\geq 40 \mathrm{mM})\end{array}$ \\
\hline $\begin{array}{c}\text { solubilization } \\
\text { degree }\end{array}$ & $\begin{array}{c}\text { increased from } \\
0.1 \text { to } 0.9 \\
\text { depending on } \\
{[\mathrm{OG}]}\end{array}$ & saturated at 0.9 \\
\hline$\lambda_{\max }$ & $\begin{array}{c}\text { blueshifted from } \\
562 \text { nm to } 548 \\
\text { nm depending on } \\
{[O G]}\end{array}$ & $\begin{array}{c}\text { constant at 548 } \\
\mathrm{nm}\end{array}$ \\
\hline $\begin{array}{c}\text { visible CD } \\
\text { spectrum }\end{array}$ & $\begin{array}{c}\text { symmetrical } \\
\text { exciton }\end{array}$ & no signal \\
\hline $\begin{array}{c}\text { structural } \\
\text { stability }\end{array}$ & $\begin{array}{c}\text { destabilized in } \\
\text { the dark (thermal } \\
\text { bleaching) }\end{array}$ & $\begin{array}{c}\text { destabilized } \\
\text { under illumination } \\
\text { (photobleaching) }\end{array}$ \\
\hline
\end{tabular}

The critical micelle concentration (CMC) of $O G$ is $25 \mathrm{mM}$, it could be understood bR was not solubilized below $25 \mathrm{mM}$. The $\mathrm{CMC}$ of $\mathrm{OG}$ formed monomeric bR-OG complex micelle was thought around $40 \mathrm{mM}$, because solubilization degrees were saturated above $40 \mathrm{mM}$. Previous reports based on complex micelle size and MRD measurements, solubilized $b R$ with about $40 \mathrm{mM}$ of $\mathrm{OG}$ was monomeric state $(24,28)$. The blueshift of $\lambda_{\max }$ at approximately $14 \mathrm{~nm}$ occurred up to $40 \mathrm{mM}$ depending on $\mathrm{OG}$ concentrations was able to thought two interpretations; The transition of 
retinal isomerization state and the change of local conformation around the Schiff base, such as the distance between D85 and the Schiff base $(19,26,27)$. In the case of solubilization with TX, the blueshift of $\lambda_{\max }$ was caused by minimal-change of local conformation instead of retinal isomerization (19). According to the report by Sonoyama et al., on the other hands, retinal isomerization to 13-cis configuration was observed accompany with $\alpha$ ll-to- $\alpha$ l conformational change of transmembrane helices (20). Thus, it was thought that both retinal isomerization and change of local conformation caused the blueshift in the case of OG.

Correlation between inter/intra molecular interaction and structural stability of bR was discussed below based on difference of stability and visible $C D$ band by $O G$ concentration. At phase 1, symmetrical $C D$ exciton bands were observed in the visible region and thermal stability became lower depending on OG concentration. These unique symmetrical exciton bands in visible $C D$ is construable that positive component indicate local conformation of intra molecular is subtracted from asymmetric band shown in native bR $(19,21-23)$. Consequently, symmetrical bands interpreted the reflection that protein-protein interaction remained and local conformation of intra molecular changed from native $b R$. OG has the effect to solubilize $\mathrm{bR}$ molecules and unstabilize by change of intra molecular interaction. At phase 2, visible CD signal was disappeared completely and photobleaching was observed in addition to thermal bleaching. This fact reconfirmed that protein-protein interaction is important for structural stability of bR in functional cycle because there was no significantly band in visible $C D$ indicated that protein-protein interaction was disappeared.

Association between visible $C D$ signal and stability was discussed below by comparison with TX solubilized $b R$. In the case of TX, solubilized bR was occurred only photobleaching without thermal bleaching, then in visible $C D$, exciton band disappeared and positive broad band reflected local conformation of intra molecular bR. Interestingly, another part of two components that compose asymmetrical exciton band appeared in $O G$ and $T X$, respectively. In a word, both $O G$ and $T X$ effect on $b R$ are quite different even though non-ion detergent. It also suggested that there were conditions in $\mathrm{OG}$ solubilized $\mathrm{bR}$ by the unit of trimer or dimer though TX solubilized bR were completely monomeric state (19). In TX solubilized bR, protein-protein interaction disappeared completely with local conformation preserved as well as native, and the stability of $b R$ only in functional photocycle has decreased remarkably (19). In the case of OG, on the other hands, local conformation was in disorder with protein-protein interaction preserved and ground state bR were destabilized.

Among two components of symmetrical visible $C D$ in native $b R$, broad positive peak linked intra molecular interaction and symmetrical exciton band reflected protein-protein interaction deeply related to the structural stability of $b R$ in ground state and functional photocycle, respectively. It was suggested the structural stability of bR in ground and functional state could be evaluated non-destructively by $C D$ measurement in visible region.

\section{REFERENCES}

[1] Bogomolni, R. A., Baker, R. A., Lozier, R. H., Stoeckenius, W., 1976, Light-driven proton translocations in Halobacterium halobium, Biochim. Biophys. Acta., 440, pp. 68-88.

[2] Henderson, R., Unwin, P. N. T., 1975, Three-dimensional model of purple membrane obtained by electron microscopy, Nature, 257, pp. 28-32.

[3] Grigorieff, N., Ceska, T. A., Downing, K. H., Baldwin, J. M., Henderson, R., 1996, Electron-crystallographic refinement of the structure of bacteriorhodopsin, J. Mol. Biol., 259, pp. 393-421.

[4] Lozier, R. H., Bogomolni, R. A., Stoeckenius, W., 1975, Bacteriorhodopsin: a light-driven proton pump in Halobacterium halobium, Biophys. J., 15, pp. 955-962.

[5] Lanyi, J. K., 1993, Proton translocation mechanism and energetic in the light-driven pump bacteriorhodopsin, Biochim. Biophys. Acta., 1183, pp. 241-261.

[6] Lanyi, J. K., Schobert, B., 2003, Mechanism of proton transport in bacteriorhodopsin from crystallographic structures of the K, L, M1, M2, and M2' intermediates of the photocycle, J. Mol. Biol., 341, pp. 439-450.

[7] Edman, K., Royant, A., Larsson, G., Jacobson, F., Taylor, T., van der Spoel, D., Landau, E. M., Pebay-Peyroula E., Neutze, R., 2004, Deformation of helix $C$ in the low temperature L-intermediate of bacteriorhodopsin, J. Biol. Chem., 279, pp. 2147-2158.

[8] Takeda, K., Matsui, Y., Kamiya, N., Adachi, S., Okumura, H., Kouyama, T., 2004, Crystal structure of the $\mathrm{M}$ intermediate of bacteriorhodopsin: Allosteric 
structural changes mediated by sliding movement of a transmembrane helix, J. Mol. Biol., 341, pp. 1023-1027.

[9] Henderson, R., Baldwin, J. M., Ceska, T. A., Zemlin, F., Beckmann, E., Downing, K. H., 1990, Model for the structure of bacteriorhodopsin based on high-resolution electron cryomicroscopy, J. Mol. Biol., 213, pp. 899-929.

[10] Mitsuoka, K., Hirai, T., Murata, K., Miyazawa, A., Kidera, A., Kimura, Y., Fujiyoshi, Y., 1999, The structure of bacteriorhodopsin at 3.0 A resolution based on electron crystallography: Implication of the charge distribution, J. Mol. Biol., 286, pp. 861-882.

[11] Luecke, H., Schobert, B., Richter, H. T., Cartailler, J. P., Lanyi, J. K., 1999, Structure of bacteriorhodopsin at 1.55 A resolution, J. Mol. Biol., 291, pp. 899-911.

[12] Etoh, A., Itoh, H., Mitaku, S., 1997, Light-induced denaturation of bacteriorhodopsin just above melting point of two-dimensional crystal, J. Phys. Soc. J., 66, pp. 975-978.

[13] Yokoyama, Y., Sonoyama, M., Mitaku, S., 2002, Irreversible photobleaching of bacteriorhodopsin in a high-temperature intermediate state, J. Biochem., 131, pp. 785-790.

[14] Yokoyama, Y., Sonoyama, M., Mitaku, S., 2004, Inhomogeneous stability of bacteriorhodopsin in purple membrane against photobleaching at high temperature, Proteins, 54, pp. 442-454.

[15] Sonoyama, M., Mitaku, S., 2004, High-temperature intermediate state of bacteriorhodopsin prior to the premelting transition of purple membrane revealed by reactivity with hydrolysis reagent hydroxylamine, $\mathrm{J}$. Phys. Chem. B, 108, pp. 19496-19500.

[16] Yokoyama, Y., Sonoyama, M., Nakano, T., Mitaku, S., 2007, Structural changes of bacteriorhodopsin in the purple membrane above $\mathrm{pH} 10$ decreases heterogeneity of the irreversible photobleaching components, J. Biochem., 142, pp. 325-333.

[17] Yokoyama, Y., Sonoyama, M., Mitaku, S., 2010, Structural changes in bacteriorhodopsin in purple membranes induced by irreversible photobleaching with heterogeneous and homoheneous stability, Photochem. photobiol., 86, pp. 297-301.

[18] Mukai, Y., Kamo, N., Mitaku, S., 1999, Light-induced denaturation of bacteriorhodopsin solubilized by octyl-?-glucoside, Protein Eng., 12, pp. 755-759.

[19] Sasaki, T., Sonoyama, M., Demura, M., Mitaku, S., 2005, Photobleaching of bacteriorhodopsin solubilized with Triton X-100, Photochem. Photobiol., 81, pp. 1131-1137.

[20] Sonoyama, M., Hasegawa, T., Nakano, T., Mitaku, S, 2004, Isomerization of retinal chromophore and conformational changes in membrane protein bacteriorhodopsin by solubilization with a mild non-ionic detergent, n-octyl-beta-glucoside: an FT-Raman and FT-IR spectroscopic study., Vibr. Spectr., 35, pp. 115-119.

[21] Heyn, M. P., Bauer, P. J., Dencher, N. A., 1975, A natural $C D$ label to probe the structure of the purple membrane from Halobacterium halobium by means of exciton coupling effects, Biochem. Biophys. Res. Commun., 67, pp. 897-903.

[22] Bauer, P. J., Dencher, N. A., 1976, Evidence for chromophore-chromophore interactions in the purple membrane from reconstitution experiments of the chromophore-free membrane, Biophys. Struct. Mech., 2, pp. 79-92.

[23] Isenbarger, T. A., Krebs, M. P., 2001, Thermodynamic stability of the bacteriorhodopsin lattice as measured by lipid dilution, Biochemistry, 40, pp. 11923-11931.

[24] Dencher, N. A., Heyn, M. P., 1978, Formation and properties of bacteriorhodopsin monomers in the non-ionic detergents octyl-?-D-glucoside and Triton X-100, FEBS lett., 96, pp. 322-326.

[25] Oesterhelt, D., Stoeckenius, W., 1974, Isolation of the cell membrane of Halobacterium halobium and its fractionation into red and purple membrane, Methods Enzymol., 31, pp. 667-678.

[26] Wang, J. P., Link, S., Heyes, C. D., El-Sayed, M. A., 2002, Comparison of the dynamics of the primary events of bacteriorhodopsin in its trimeric and monomeric states, Biophys. J., 83, pp. 1557-1566.

[27] Milder, S. J., Thorgeirsson, T. E., Miercke, L. J. W., Stroud, R. M., Kliger, D. S., 1991, Effects of detergent environments on the photocycle of purified monomeric bacteriorhodopsin, Biochemistry, 30, pp. 1751-1761.

[28] Gottschalk, M., Dencher, N. A., Halle, B., 2001, Microsecond exchange of internal water molecules in bacteriorhodopsin, J. Mol. Biol., 311, pp. 605-621.

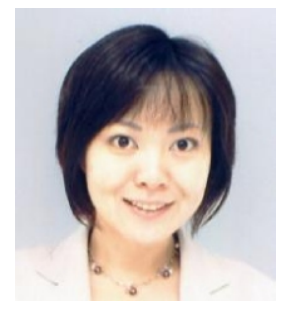

Yuri Mukai is a lecturer of Department of Electronics and Bioinformatics, School of Science and Technology, Meiji University, Japan. 